\title{
Clinical Features and Prevalence of Spondyloarthritis in a Cohort of Italian Patients Presenting with Acute Nongranulomatous Anterior Uveitis
}

\author{
Elena Bolletta $\mathbb{D}^{1}{ }^{1}$ Pierluigi Macchioni, ${ }^{2}$ Giorgia Citriniti, ${ }^{2}$ Valentina Mastrofilippo, ${ }^{1}$ \\ Raffaella Aldigeri, ${ }^{3}$ Luca De Simone ${ }^{(D)}{ }^{1}$ Fabrizio Gozzi, ${ }^{1}$ Chantal Adani, ${ }^{1}$ \\ Anna Sangiovanni, ${ }^{1}$ Chiara Posarelli, ${ }^{4}$ Michele Figus, ${ }^{4}$ Francesco Muratore, ${ }^{2}$ \\ Nicolò Pipitone, ${ }^{2}$ Carlo Salvarani, ${ }^{2,5}$ and Luca Cimino ${ }^{10}{ }^{1,5}$ \\ ${ }^{1}$ Ocular Immunology Unit, Azienda USL-IRCCS of Reggio Emilia, Reggio Emilia, Italy \\ ${ }^{2}$ Rheumatology Unit, Azienda USL-IRCCS of Reggio Emilia, Reggio Emilia, Italy \\ ${ }^{3}$ Department of Medicine and Surgery, University of Parma, Parma, Italy \\ ${ }^{4}$ Department of Surgical, Medical and Molecular Pathology and Critical Care Medicine, University of Pisa, Pisa, Italy \\ ${ }^{5}$ Department of Surgery, Medicine, Dentistry and Morphological Sciences, with Interest in Transplants, Oncology and \\ Regenerative Medicine, University of Modena and Reggio Emilia, Modena, Italy
}

Correspondence should be addressed to Luca Cimino; 1.cimino64@gmail.com

Pierluigi Macchioni and Giorgia Citriniti contributed equally to this work.

Received 31 December 2020; Revised 2 November 2021; Accepted 24 December 2021; Published 18 January 2022

Academic Editor: Francesca Santilli

Copyright ( 2022 Elena Bolletta et al. This is an open access article distributed under the Creative Commons Attribution License, which permits unrestricted use, distribution, and reproduction in any medium, provided the original work is properly cited.

\begin{abstract}
Purpose. To describe the clinical features of acute nongranulomatous anterior uveitis (NGAU) patients and to estimate the prevalence of concomitant spondyloarthritis (SpA). Methods. Retrospective study of consecutive patients affected by NGAU referred to the Ocular Immunology Unit of the AUSL-IRCCS di Reggio Emilia, Italy, between January 2016 and January 2019. All patients underwent ophthalmic evaluation and blood test with HLA-B27 typing and were referred to a rheumatologist to identify any undiagnosed SpA. SpA was classified according to the Assessment of SpondyloArthritis international Society (ASAS) criteria in axial or peripheral SpA. Patients were divided into two groups: NGAU with associated SpA (SpA+) and NGAU without SpA (SpA-). Clinical and demographic features of the two groups, including sex, HLA-B27, family history of rheumatic disease, uveitis laterality, course, and severity of ocular inflammation, complications, and treatment, were compared. Results. Ninety-nine patients with NGAU were enrolled, of whom 36 (36\%) with a diagnosis of SpA: 14 with peripheral SpA and 22 with axial SpA. The prevalence of SpA was higher in HLA-B27-positive patients than in HLA-B27-negative patients $(50 \%$ vs. $15 \%, p<0.0001)$. The multivariate logistic regression $\left(R^{2}=0.28\right)$ for $\mathrm{SpA}$ diagnosis identified as significant predictive factors: age at diagnosis (odds ratio $[\mathrm{OR}]=0.95,95 \%$ confidence interval $[\mathrm{CI}]$ : 0.91-0.99) and HLA-B27+ $(\mathrm{OR}=5.32,95 \% \mathrm{CI}$ : 1.80-15.70). Conclusions. Our results confirmed the high prevalence of undiagnosed SpA in patients with NGAU, suggesting that, regardless of HLA-B27 status, in the presence of IBP and/or peripheral arthritis, patients with NGAU must be referred to the rheumatologist to allow earlier diagnosis.
\end{abstract}

\section{Introduction}

Acute anterior uveitis (AAU) is the most common type of uveitis worldwide, with higher prevalence in Western countries, where it accounts for approximately $50-92 \%$ of cases
[1]. According to recent epidemiological studies, it represents $49-58 \%$ of uveitis in Italy [2-4].

A distinction between granulomatous and nongranulomatous uveitis is mandatory for a correct diagnostic evaluation of anterior uveitis [5]. Most cases of acute 
TABLE 1: Main characteristics of study population according to SpA diagnosis.

\begin{tabular}{|c|c|c|c|c|c|c|c|}
\hline & Total $(n=99)$ & & SpA- $(n=63)$ & & $\mathrm{SpA}+(n=36)$ & & \\
\hline & $\begin{array}{c}\text { Mean } \pm \text { SD/median } \\
(\mathrm{IQR})\end{array}$ & $N(\%)$ & $\begin{array}{c}\text { Mean } \pm \text { SD/median } \\
(\mathrm{IQR})\end{array}$ & $N(\%)$ & $\begin{array}{c}\text { Mean } \pm \text { SD/median } \\
(\mathrm{IQR})\end{array}$ & $N(\%)$ & $p$ value \\
\hline Age (yrs) & $46 \pm 13$ & & $48 \pm 12$ & & $43 \pm 13$ & & 0.05 \\
\hline Age $<45$ yrs & & $\begin{array}{c}47 \\
(48)\end{array}$ & & $\begin{array}{c}25 \\
(40)\end{array}$ & & $\begin{array}{l}22 \\
(61)\end{array}$ & $0.04^{*}$ \\
\hline $\begin{array}{l}\text { Age at uveitis diagnosis } \\
\text { (yrs) }\end{array}$ & $42 \pm 13$ & & $45 \pm 12$ & & $37 \pm 14$ & & $0.005^{* *}$ \\
\hline $\begin{array}{l}\text { Uveitis diagnostic delay } \\
(\mathrm{mo})\end{array}$ & $3(0-32)$ & & $5(0-36)$ & & $1(0-23)$ & & 0.28 \\
\hline \multicolumn{8}{|l|}{ Sex } \\
\hline M & & $\begin{array}{c}38 \\
(38)\end{array}$ & & $\begin{array}{c}24 \\
(38)\end{array}$ & & $\begin{array}{c}14 \\
(38)\end{array}$ & \multirow{2}{*}{0.94} \\
\hline $\mathrm{F}$ & & $\begin{array}{c}61 \\
(62)\end{array}$ & & $\begin{array}{l}39 \\
(62)\end{array}$ & & $\begin{array}{c}22 \\
(62)\end{array}$ & \\
\hline BMI $\left(\mathrm{kg} / \mathrm{m}^{2}\right)$ & $25 \pm 5$ & & $25 \pm 5$ & & $25 \pm 6$ & & 0.88 \\
\hline Family history of $\mathrm{SpA}^{\dagger}$ & & $\begin{array}{c}39 \\
(39)\end{array}$ & & $\begin{array}{c}22 \\
(35)\end{array}$ & & $\begin{array}{c}17 \\
(47)\end{array}$ & 0.23 \\
\hline Current smoker & & $\begin{array}{c}23 \\
(23)\end{array}$ & & $\begin{array}{c}14 \\
(22)\end{array}$ & & $9(25)$ & 0.80 \\
\hline Diabetes mellitus & & $3(3)$ & & $2(3)$ & & $1(3)$ & 0.91 \\
\hline Dyslipidemia & & $\begin{array}{c}25 \\
(25)\end{array}$ & & $\begin{array}{c}16 \\
(25)\end{array}$ & & $9(25)$ & 0.75 \\
\hline Hypertension & & $\begin{array}{c}13 \\
(13)\end{array}$ & & $9(14)$ & & $4(11)$ & 0.65 \\
\hline HLA-B27 + & & $\begin{array}{c}60 \\
(60)\end{array}$ & & $\begin{array}{c}30 \\
(48)\end{array}$ & & $\begin{array}{c}30 \\
(83)\end{array}$ & $<0.001^{* * *}$ \\
\hline Axial SpA & & $\begin{array}{c}22 \\
(22)\end{array}$ & & $0(0)$ & & $\begin{array}{c}22 \\
(61)\end{array}$ & $\mathrm{Nd}$ \\
\hline Peripheral SpA & & $\begin{array}{c}14 \\
(14)\end{array}$ & & $0(0)$ & & $\begin{array}{c}14 \\
(39)\end{array}$ & $\mathrm{Nd}$ \\
\hline IBP (ASAS criteria) & & $\begin{array}{c}24 \\
(24)\end{array}$ & & $2(3)$ & & $\begin{array}{l}22 \\
(61)\end{array}$ & $<0.001^{* * *}$ \\
\hline Enthesitis & & $\begin{array}{c}13 \\
(13)\end{array}$ & & $0(0)$ & & $\begin{array}{l}13 \\
(36)\end{array}$ & $<0.001^{* * *}$ \\
\hline Dactylitis & & $7(7)$ & & $0(0)$ & & $7(19)$ & $<0.001^{* * *}$ \\
\hline IBD & & $5(5)$ & & $5(8)$ & & $0(0)$ & 0.22 \\
\hline Psoriasis & & $\begin{array}{l}10 \\
(10)\end{array}$ & & $7(11)$ & & $3(8)$ & 0.66 \\
\hline Urethritis/cervicitis & & $\begin{array}{c}12 \\
(12)\end{array}$ & & $7(11)$ & & $5(14)$ & 0.68 \\
\hline Peripheral arthritis & & $\begin{array}{c}19 \\
(19)\end{array}$ & & $0(0)$ & & $\begin{array}{c}19 \\
(53)\end{array}$ & $<0.0001^{* * *}$ \\
\hline \multicolumn{8}{|c|}{ Ophthalmic evaluation: } \\
\hline \multicolumn{8}{|l|}{ Uveitis } \\
\hline Acute & & $\begin{array}{c}29 \\
(29)\end{array}$ & & $\begin{array}{c}16 \\
(25)\end{array}$ & & $\begin{array}{l}13 \\
(36)\end{array}$ & \multirow{2}{*}{0.26} \\
\hline Recurrent & & $\begin{array}{c}70 \\
(71)\end{array}$ & & $\begin{array}{l}47 \\
(75)\end{array}$ & & $\begin{array}{l}23 \\
(64)\end{array}$ & \\
\hline Bilateral uveitis & & $\begin{array}{c}40 \\
(40)\end{array}$ & & $\begin{array}{c}27 \\
(43)\end{array}$ & & $\begin{array}{l}13 \\
(36)\end{array}$ & 0.51 \\
\hline Hypopyon & & $2(2)$ & & $0(0)$ & & $2(6)$ & 0.06 \\
\hline Synechiae & & $\begin{array}{c}29 \\
(29)\end{array}$ & & $\begin{array}{c}21 \\
(33)\end{array}$ & & $8(22)$ & 0.24 \\
\hline Cataract & & $\begin{array}{c}19 \\
(19)\end{array}$ & & $\begin{array}{c}12 \\
(19)\end{array}$ & & $7(19)$ & 0.96 \\
\hline
\end{tabular}

Legend: SD: standard deviation; IQR: interquartile range; SpA: spondyloarthritis; F: female; M: male; BMI: body max index; HLA: human leukocyte antigen; IBP: inflammatory back pain; ASAS: Assessment of SpondyloArthritis international Society; IBD: inflammatory bowel disease. ${ }^{\dagger}$ Family history of AS, psoriasis, reactive arthritis, uveitis, or IBD in a first-degree relative (father, mother, sisters, brothers, and children) or second-degree relative (maternal and paternal grandparents, aunts, uncles, nieces, and nephews). 
TABLE 2: Main characteristics of study population according to male sex.

\begin{tabular}{|c|c|c|c|c|c|c|c|}
\hline & \multicolumn{2}{|c|}{ Total males $(n=38)$} & \multicolumn{2}{|l|}{$\mathrm{SpA}-(n=24)$} & \multicolumn{2}{|l|}{$\mathrm{SpA}+(n=14)$} & \multirow[b]{2}{*}{$p$ value } \\
\hline & $\begin{array}{c}\text { Mean } \pm \text { SD/median } \\
(\mathrm{IQR})\end{array}$ & $N(\%)$ & $\begin{array}{c}\text { Mean } \pm \text { SD/median } \\
(\mathrm{IQR})\end{array}$ & $N(\%)$ & $\begin{array}{c}\text { Mean } \pm \text { SD/median } \\
(\mathrm{IQR})\end{array}$ & $N(\%)$ & \\
\hline Age (yrs) & $48 \pm 12$ & & $51 \pm 10$ & & $44 \pm 14$ & & 0.08 \\
\hline Age $<45$ yrs & & $\begin{array}{c}25 \\
(66)\end{array}$ & & $\begin{array}{c}19 \\
(79)\end{array}$ & & $6(43)$ & $0.02^{*}$ \\
\hline $\begin{array}{l}\text { Age at uveitis diagnosis } \\
\text { (yrs) }\end{array}$ & $45 \pm 11$ & & & & & & $0.02^{*}$ \\
\hline $\begin{array}{l}\text { Uveitis diagnostic delay } \\
\text { (mo) }\end{array}$ & $5.5(0-35)$ & & $5.5(0-31)$ & & $9.5(0-50)$ & & 0.94 \\
\hline BMI $\left(\mathrm{kg} / \mathrm{m}^{2}\right)$ & $26 \pm 4$ & & $26 \pm 4$ & & $27 \pm 5$ & & 0.81 \\
\hline Family history of $\mathrm{SpA}^{\dagger}$ & & $\begin{array}{c}11 \\
(29)\end{array}$ & & $7(29)$ & & $4(29)$ & 0.97 \\
\hline Current smoker & & $\begin{array}{c}11 \\
(29)\end{array}$ & & $8(35)$ & & $3(23)$ & 0.75 \\
\hline Diabetes mellitus & & $1(3)$ & & $1(4)$ & & $0(0)$ & 0.44 \\
\hline Dyslipidemia & & $7(18)$ & & $5(21)$ & & $2(14)$ & 0.72 \\
\hline Hypertension & & $5(13)$ & & $4(17)$ & & $1(7)$ & 0.40 \\
\hline HLA-B27 + & & $\begin{array}{c}21 \\
(55)\end{array}$ & & $9(38)$ & & $\begin{array}{c}12 \\
(86)\end{array}$ & $0.004^{* *}$ \\
\hline Axial SpA & & $9(64)$ & & $0(0)$ & & $9(64)$ & $\mathrm{Nd}$ \\
\hline Peripheral SpA & & $5(13)$ & & $0(0)$ & & $5(36)$ & $\mathrm{Nd}$ \\
\hline IBP (ASAS criteria) & & $\begin{array}{l}10 \\
(26)\end{array}$ & & $1(4)$ & & $9(64)$ & $<0.001^{* * *}$ \\
\hline Enthesitis & & $5(13)$ & & $0(0)$ & & $5(36)$ & $0.002^{* *}$ \\
\hline Dactylitis & & $3(8)$ & & $0(0)$ & & $3(21)$ & $0.02^{*}$ \\
\hline IBD & & $2(5)$ & & $2(8)$ & & $0(0)$ & 0.54 \\
\hline Psoriasis & & $4(11)$ & & $2(8)$ & & $2(14)$ & 0.56 \\
\hline Urethritis/cervicitis & & $5(13)$ & & $3(13)$ & & $2(14)$ & 0.87 \\
\hline Peripheral arthritis & & $5(13)$ & & $0(0)$ & & $5(36)$ & $0.002^{* *}$ \\
\hline \multicolumn{8}{|c|}{ Ophthalmic evaluation: } \\
\hline \multicolumn{8}{|l|}{ Uveitis } \\
\hline Acute & & $\begin{array}{l}11 \\
(29)\end{array}$ & & $8(35)$ & & $3(21)$ & \multirow{2}{*}{0.44} \\
\hline Recurrent & & $\begin{array}{c}27 \\
(71)\end{array}$ & & $\begin{array}{c}16 \\
(67)\end{array}$ & & $\begin{array}{c}11 \\
(79)\end{array}$ & \\
\hline Bilateral uveitis & & $\begin{array}{c}17 \\
(45)\end{array}$ & & $\begin{array}{c}10 \\
(42)\end{array}$ & & $7(50)$ & 0.62 \\
\hline Hypopyon & & $0(0)$ & & $0(0)$ & & $0(0)$ & $\mathrm{Nd}$ \\
\hline Synechiae & & $\begin{array}{l}10 \\
(26)\end{array}$ & & $7(29)$ & & $3(21)$ & 0.60 \\
\hline Cataract & & $7(18)$ & & $5(21)$ & & $2(14)$ & 0.61 \\
\hline
\end{tabular}

Legend: BMI: body max index; SpA: spondyloarthritis; HLA: human leukocyte antigen; IBP: inflammatory back pain; ASAS: Assessment of SpondyloArthritis international Society; IBD: inflammatory bowel disease. ${ }^{\dagger}$ Family history of AS, psoriasis, reactive arthritis, uveitis, or IBD in a first-degree relative (father, mother, sisters, brothers, and children) or second-degree relative (maternal and paternal grandparents, aunts, uncles, nieces, and nephews).

nongranulomatous anterior uveitis (NGAU) are associated with autoimmune diseases, primarily spondyloarthritis (SpA) [6]. AAU in SpA patients typically occurs as recurrent or alternating unilateral NGAU with conjunctival and ciliary injection, resulting in the visible redness of the affected eye. A clinical assessment of intraocular inflammation by slitlamp examination shows intraocular cells and the presence of protein exudation in the aqueous humor of the anterior chamber. This can lead to direct leukocyte sedimentation in the anterior chamber ("hypopyon") and to the formation of posterior synechiae as a secondary sequela, resulting in adhesions between the iris and the lens [7].

SpA is also known as seronegative spondyloarthropathies, a family of rheumatic diseases that include ankylosing 
TABLE 3: Main characteristics of study population according to female sex.

\begin{tabular}{|c|c|c|c|c|c|c|c|}
\hline & Total females $(n=$ & & SpA- $(n=39)$ & & $\mathrm{SpA}+(n=22)$ & & \\
\hline & $\begin{array}{c}\text { Mean } \pm \text { SD/median } \\
(\mathrm{IQR})\end{array}$ & $N(\%)$ & $\begin{array}{c}\text { Mean } \pm \text { SD } / \text { median } \\
(\mathrm{IQR})\end{array}$ & $N(\%)$ & $\begin{array}{c}\text { Mean } \pm \text { SD/median } \\
(\mathrm{IQR})\end{array}$ & $N(\%)$ & $p$ value \\
\hline Age (yrs) & $44 \pm 13$ & & $46 \pm 12$ & & $42 \pm 13$ & & 0.27 \\
\hline Age $<45$ yrs & & $\begin{array}{c}27 \\
(44)\end{array}$ & & $\begin{array}{c}19 \\
(49)\end{array}$ & & $8(36)$ & 0.35 \\
\hline $\begin{array}{l}\text { Age at uveitis diagnosis } \\
\text { (yrs) }\end{array}$ & $40 \pm 14$ & & $43 \pm 13$ & & $35 \pm 15$ & & $0.04^{*}$ \\
\hline $\begin{array}{l}\text { Uveitis diagnostic delay } \\
\text { (mo) }\end{array}$ & $2(0-24)$ & & $3(0-40)$ & & $1(0-8)$ & & 0.18 \\
\hline BMI $\left(\mathrm{kg} / \mathrm{m}^{2}\right)$ & $24 \pm 5$ & & $24 \pm 5$ & & $24 \pm 6$ & & 0.99 \\
\hline Family history of $\mathrm{SpA}^{\dagger}$ & & $\begin{array}{c}28 \\
(46)\end{array}$ & & $\begin{array}{c}15 \\
(39)\end{array}$ & & $\begin{array}{c}13 \\
(59)\end{array}$ & 0.12 \\
\hline Current smoker & & $\begin{array}{c}12 \\
(20)\end{array}$ & & $6(15)$ & & $6(27)$ & 0.41 \\
\hline Diabetes mellitus & & $2(3)$ & & $1(3)$ & & $1(5)$ & 0.68 \\
\hline Dyslipidemia & & $\begin{array}{c}18 \\
(30)\end{array}$ & & $\begin{array}{c}11 \\
(28)\end{array}$ & & $7(32)$ & 0.77 \\
\hline Hypertension & & $8(13)$ & & $5(13)$ & & $3(14)$ & 0.93 \\
\hline HLA-B27 + & & $\begin{array}{c}39 \\
(64)\end{array}$ & & $\begin{array}{c}21 \\
(54)\end{array}$ & & $\begin{array}{c}18 \\
(82)\end{array}$ & $0.03 *$ \\
\hline Axial SpA & & $\begin{array}{c}13 \\
(21)\end{array}$ & & $0(0)$ & & $\begin{array}{c}13 \\
(59)\end{array}$ & $\mathrm{Nd}$ \\
\hline Peripheral SpA & & $9(41)$ & & $0(0)$ & & $9(41)$ & $\mathrm{Nd}$ \\
\hline IBP (ASAS criteria) & & $\begin{array}{c}14 \\
(23)\end{array}$ & & $1(3)$ & & $\begin{array}{c}13 \\
(59)\end{array}$ & $<0.001^{* * *}$ \\
\hline Enthesitis & & $8(13)$ & & $0(0)$ & & $8(36)$ & $<0.001^{* * *}$ \\
\hline Dactylitis & & $4(7)$ & & $0(0)$ & & $4(18)$ & $0.006^{* *}$ \\
\hline IBD & & $3(5)$ & & $3(8)$ & & $0(0)$ & 0.41 \\
\hline Psoriasis & & $6(10)$ & & $5(13)$ & & $1(5)$ & 0.30 \\
\hline Urethritis/cervicitis & & $7(12)$ & & $4(10)$ & & $3(14)$ & 0.69 \\
\hline Peripheral arthritis & & $\begin{array}{c}14 \\
(23)\end{array}$ & & $0(0)$ & & $\begin{array}{c}14 \\
(64)\end{array}$ & $<0.001^{* * *}$ \\
\hline & & Op & halmic evaluation: & & & & \\
\hline Uveitis & & & & & & & \\
\hline Acute & & $\begin{array}{c}18 \\
(30)\end{array}$ & & $8(21)$ & & $\begin{array}{c}10 \\
(45)\end{array}$ & \\
\hline Recurrent & & $\begin{array}{c}43 \\
(70)\end{array}$ & & $\begin{array}{c}31 \\
(79)\end{array}$ & & $\begin{array}{c}12 \\
(55)\end{array}$ & 0.04 \\
\hline Bilateral uveitis & & $\begin{array}{c}23 \\
(38)\end{array}$ & & $\begin{array}{c}17 \\
(44)\end{array}$ & & $6(27)$ & 0.21 \\
\hline Hypopyon & & $2(3)$ & & $0(0)$ & & $2(9)$ & 0.06 \\
\hline Synechiae & & $\begin{array}{c}19 \\
(31)\end{array}$ & & $\begin{array}{c}14 \\
(36)\end{array}$ & & $5(23)$ & 0.29 \\
\hline Cataract & & $\begin{array}{c}12 \\
(20)\end{array}$ & & $7(18)$ & & $5(23)$ & 0.65 \\
\hline
\end{tabular}

Legend: SD: standard deviation; IQR: interquartile range; BMI: body max index; SpA: spondyloarthritis; HLA: human leukocyte antigen; IBP: inflammatory back pain; ASAS: Assessment of SpondyloArthritis international Society; IBD: inflammatory bowel disease. ${ }^{\dagger}$ Family history of AS, psoriasis, reactive arthritis, uveitis, or IBD in a first-degree relative (father, mother, sisters, brothers, and children) or second-degree relative (maternal and paternal grandparents, aunts, uncles, nieces, and nephews). 
TABLE 4: Main characteristics of study population according to SpA classification.

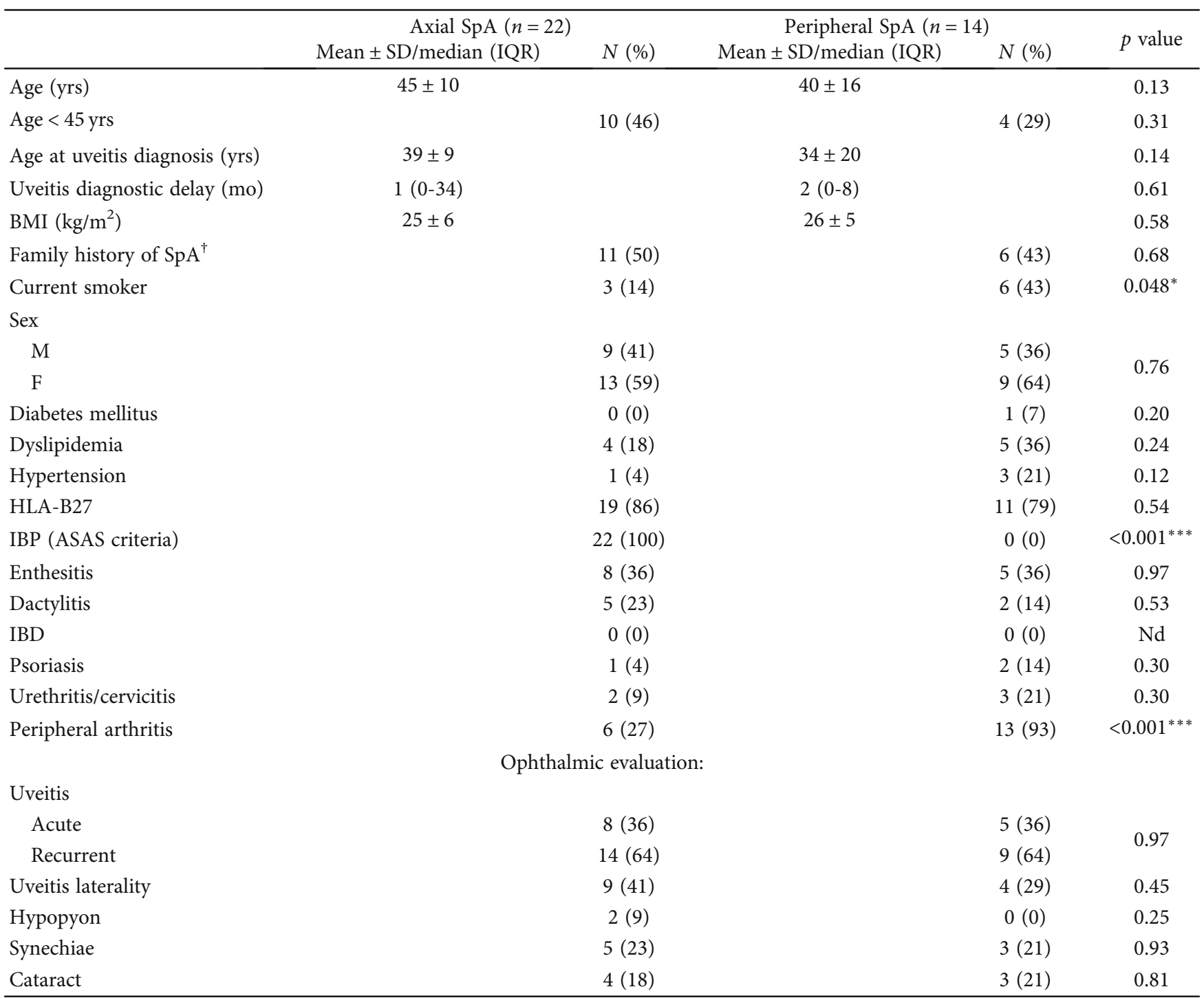

Legend: SpA: spondyloarthritis; SD: standard deviation; IQR: interquartile range; BMI: body max index; M: male; F: female; HLA: human leukocyte antigen; IBP: inflammatory back pain; ASAS: Assessment of SpondyloArthritis international Society; IBD: inflammatory bowel disease. ${ }^{\dagger}$ Family history of AS, psoriasis, reactive arthritis, uveitis, or IBD in a first-degree relative (father, mother, sisters, brothers, and children) or second-degree relative (maternal and paternal grandparents, aunts, uncles, nieces, and nephews).

spondylitis, psoriatic arthritis, arthritis associated with inflammatory bowel disease (IBD), reactive arthritis (formerly known as Reiter's syndrome), and undifferentiated SpA [8].

AAU prevalence in SpA ranges from $21 \%$ to $33 \%$, according to a recent meta-analysis [7]. Other studies report the prevalence of previously undiagnosed SpA in AAU ranging from $40 \%$ to $67 \%$; this percentage is even higher when uveitis is associated with the human leukocyte antigen(HLA-) B27 [9, 10].

Since AAU is the most frequent extra-articular manifestation of SpA and can be its first sign, ophthalmologists should refer these patients to a rheumatologist, although there are no shared guidelines defining which patients should be referred. The Dublin Uveitis Evaluation Tool (DUET) algorithm has been proposed to guide the selection of appropriate candidates [9]. Moreover, a Delphi consensus was undertaken to standardize red flags for referral to rheumatologists and to ophthalmologists of patients with rheumatic diseases and ocular involvement [11].

This study evaluated the ophthalmological and rheumatological clinical features as well as the demographics and genetics (HLA-B27) of patients with NGAU to differentiate between NGAU associated with SpA (SpA+) and NGAU without SpA (SpA-) and to help ophthalmologists to appropriately select patients for rheumatology referral.

\section{Materials and Methods}

Consecutive adult patients with NGAU referred to the Ocular Immunology Unit of the AUSL-IRCCS di Reggio Emilia, Italy, between January 2016 and January 2019 were enrolled 
TABLE 5: Main characteristics of study population according to HLA-B27 status.

\begin{tabular}{|c|c|c|c|c|c|}
\hline & \multicolumn{2}{|c|}{ HLA-B27- $(n=39)$} & \multicolumn{2}{|c|}{ HLA-B27+ $(n=60)$} & \multirow{2}{*}{$p$ value } \\
\hline & Mean \pm SD/median (IQR) & $N(\%)$ & Mean $\pm \mathrm{SD} /$ median $(\mathrm{IQR})$ & $N(\%)$ & \\
\hline Age (yrs) & $47 \pm 11$ & & $45 \pm 13$ & & 0.41 \\
\hline Age $<45$ yrs & & $24(62)$ & & $28(47)$ & 0.15 \\
\hline Age at uveitis diagnosis (yrs) & $45 \pm 12$ & & $40 \pm 14$ & & $0.049^{*}$ \\
\hline Uveitis diagnostic delay (mo) & $2(0-24)$ & & $3.5(0-33)$ & & 0.41 \\
\hline \multicolumn{6}{|l|}{ Sex } \\
\hline M & & $17(44)$ & & $21(35)$ & \multirow{2}{*}{0.39} \\
\hline $\mathrm{F}$ & & $22(56)$ & & $39(65)$ & \\
\hline BMI $\left(\mathrm{kg} / \mathrm{m}^{2}\right)$ & $26 \pm 5$ & & $24.5 \pm 5$ & & 0.08 \\
\hline Family history of $\mathrm{SpA}^{\dagger}$ & & $14(36)$ & & $25(42)$ & 0.57 \\
\hline Current smoker & & $14(36)$ & & $9(15)$ & $0.02 *$ \\
\hline Diabetes mellitus & & $1(3)$ & & $2(3)$ & 0.83 \\
\hline Dyslipidemia & & $11(28)$ & & $14(23)$ & 0.43 \\
\hline Hypertension & & $7(18)$ & & $6(10)$ & 0.25 \\
\hline Axial SpA & & $3(8)$ & & $19(32)$ & $0.005^{* *}$ \\
\hline Peripheral SpA & & $3(8)$ & & $11(18)$ & 0.14 \\
\hline SpA & & $6(15)$ & & $30(50)$ & $<0.0001^{* * *}$ \\
\hline IBP (ASAS criteria) & & $5(13)$ & & $19(32)$ & $0.01^{*}$ \\
\hline Enthesitis & & $3(8)$ & & $10(17)$ & 0.20 \\
\hline Dactylitis & & $1(3)$ & & $6(10)$ & 0.16 \\
\hline IBD & & $2(5)$ & & $3(5)$ & 0.93 \\
\hline Psoriasis & & $4(10)$ & & $6(10)$ & 0.97 \\
\hline Urethritis/cervicitis & & $5(13)$ & & $7(12)$ & 0.86 \\
\hline Peripheral arthritis & & $4(10)$ & & $15(25)$ & 0.07 \\
\hline \multicolumn{6}{|c|}{ Ophthalmic evaluation: } \\
\hline \multicolumn{6}{|l|}{ Uveitis } \\
\hline Acute & & $13(33)$ & & $16(27)$ & \multirow{2}{*}{0.48} \\
\hline Recurrent & & $26(67)$ & & $44(73)$ & \\
\hline Uveitis laterality & & $18(46)$ & & $22(37)$ & 0.35 \\
\hline Hypopyon & & $0(0)$ & & $2(3)$ & 0.25 \\
\hline Synechiae & & $17(44)$ & & $12(20)$ & $0.01^{*}$ \\
\hline Cataract & & $9(23)$ & & $10(17)$ & 0.43 \\
\hline
\end{tabular}

Legend: HLA: human leukocyte antigen; SD: standard deviation; IQR: interquartile range; M: male; F: female; BMI: body max index; SpA: spondyloarthritis; IBP: inflammatory back pain; ASAS: Assessment of SpondyloArthritis international Society; IBD: inflammatory bowel disease. ${ }^{\dagger}$ Family history of AS, psoriasis, reactive arthritis, uveitis, or IBD in a first-degree relative (father, mother, sisters, brothers, and children) or second-degree relative (maternal and paternal grandparents, aunts, uncles, nieces, and nephews).

in this retrospective study. Patients were referred by ophthalmologists, general practitioners, or rheumatologists.

NGAU is defined as acute onset uveitis with anterior chamber reaction without granulomatous keratic precipitates by the Standardization of Uveitis Nomenclature (SUN) Working Group guidelines [12]. Exclusion criteria in this study were the presence of other causes of uveitis, previously diagnosed $\mathrm{SpA}$ and/or no HLA test result available.

All patients underwent a complete ophthalmic evaluation, including best corrected visual acuity (BCVA), intraocular pressure (IOP), slit-lamp examination of the anterior segment with clinical evaluation of anterior chamber inflammation, and of the fundus after pupillary dilatation.
Blood test with HLA-B27 typing was also performed in all patients, and subsequently, they were referred to a rheumatologist to identify any undiagnosed SpA. A careful family history was taken to highlight any immune-mediated systemic diseases, including $\mathrm{SpA}$, psoriasis, and IBD, i.e., Crohn's disease and ulcerative colitis (UC). Other parameters recorded were body mass index (BMI), smoking status, comorbidities, age at first episode of uveitis, age at diagnosis of $\mathrm{SpA}$, and the presence and age at onset of inflammatory back pain (IBP), as defined by the Assessment of SpondyloArthritis international Society (ASAS) criteria. According to these criteria, IBP is chronic back pain (CBP) lasting more than 3 months, with four out of five of the following 
parameters: age at onset $<40$ years, insidious onset, improvement with exercise, no improvement with rest, and pain at night (with improvement upon getting up). SpA was classified according to the ASAS criteria as axial or peripheral SpA $[13,14]$. Patients were divided into two groups: NGAU with associated SpA (SpA+) and NGAU without SpA (SpA). Rheumatological examination included the Bath Ankylosing Spondylitis Disease Activity Index (BASDAI) to evaluate disease activity of axial $\mathrm{SpA}$. Sacroiliac radiography or magnetic resonance imaging (MRI) and ultrasound of the entheses and peripheral joints were performed when requested by the rheumatologist.

The study was conducted according to the Declaration of Helsinki and was approved by the local Ethics Committee (2019/0100242). Informed consent was obtained from all patients at enrollment.

Statistical analysis was performed using the SPSS software, v.27. Significance was defined as $p<0.05$ (two-tailed). To describe the study sample, we used frequencies, mean and standard deviation, or median and interquartile range, depending on the distribution. Comparisons were performed using $t$-test or chi-square test. The association between clinical variables and $\mathrm{SpA}$ was determined using Pearson's correlation coefficient and multivariate logistic regression model.

\section{Results}

Ninety-nine consecutive patients with NGAU were enrolled in the study: 38 males (38\%) and 61 females (62\%), with a mean age of $46 \pm 13$ years (range $20-75$ years). Sixty (60\%) subjects with NGAU were HLA-B27+. Most of the patients (71\%) had recurrent uveitis, $40 \%$ presented alternant bilateral involvement, and $29 \%$ had posterior synechiae, the most frequent complication. The main characteristics of the patients and clinical findings are summarized in Table 1 and divided by sex in Tables 2 and 3.

A total of 36 (36\%) patients were diagnosed with SpA: 14 patients with peripheral SpA and 22 with axial SpA (ASAS criteria) (Table 4).

No differences in BMI, sex, or smoking status were found between the SpA+ and SpA-groups.

Age at diagnosis of uveitis was significantly lower in SpA + patients $(p=0.005)$ IBP and peripheral arthritis incidence were significantly higher in the SpA+ group $(p<0.001)$, as was HLA-B27 positivity $(p<0.001)$ (Table 1$)$. No significant differences in ophthalmologic features, including recurrence of uveitis, laterality, hypopyon, synechiae, and cataract, were observed between SpA+ and SpA-patients.

Age at diagnosis of uveitis in patients with positive HLAB27 was lower than in patients with negative HLA-B27 (mean age 40 vs. 45 years; $p=0.049^{*}$ ) (Table 5).

The prevalence of both axial and peripheral $\mathrm{SpA}$ was higher in HLA-B27+ patients (19/60 [31.7\%] and 11/60 [18.3\%], respectively) than in HLA-B27- patients $(3 / 39$ [7.7\%] and $3 / 39$ [7.7\%]) $(p=0.005 * *$ and $p=0.14)$ (Table 5).

The multivariate logistic regression $\left(R^{2}=0.28\right)$ for SpA diagnosis, which included age at diagnosis, sex, ocular bilateral involvement, acute/recurrent trend, and HLA-B27 pos-

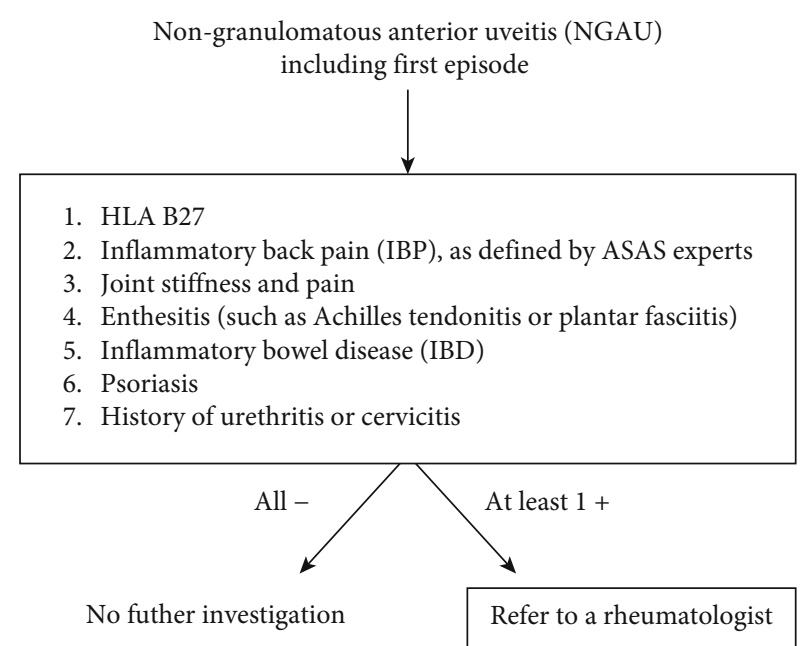

Legend: HLA = human leukocyte antigen; ASAS = assessment of spondyloarthritis international society.

FIgURe 1: Reggio Emilia Uveitis Spondyloarthritis Interdisciplinary Approach (REUSIA) algorithm. Legend: HLA: human leukocyte antigen; ASAS: Assessment of SpondyloArthritis international Society.

itivity, identified as significant predictive factors of SpA age at diagnosis (OR = 0.95, 95\% CI: 0.91-0.99) and HLA-B27+ $(\mathrm{OR}=5.32$, 95\% CI: 1.80-15.70).

Twenty-eight subjects were previously treated with systemic steroids, while 92 with topical steroids $(100 \%$ in SpA + vs. $88 \%$ in SpA-, $p=0.017)$. Eight patients were prescribed with biologics, $13 \%$ in the SpA+ group vs. $4 \%$ in the SpA- $(p=0.09)$. One SpA-patient was treated with biologic therapy with adalimumab for UC.

\section{Discussion}

Anterior uveitis is the most common extra-articular manifestation of SpA and is characterized by nongranulomatous clinical features. A well-structured screening of patients affected by NGAU could allow early diagnosis, considering that the mean diagnostic delay of $\mathrm{SpA}$ from symptom onset ranges from 4.9 to 6.8 years $[15,16]$. It must be taken into account that delayed diagnosis is associated with worse spinal functional impairment, greater radiographic progression, reduced response to treatment, and poorer quality of life $[17,18]$.

The SENTINEL Interdisciplinary Collaborative Project was a multicenter prospective observational study on the largest cohort of patients with anterior uveitis who were systematically screened for associated and underdiagnosed SpA [9]. This and other previous studies report the high prevalence of undiagnosed $\mathrm{SpA}$ in patients with anterior uveitis: $67.7 \%$ by Juanola et al. and $40 \%$ by Haroon et al. $[9,10]$.

Our study confirms this high prevalence (36\%), despite some differences in the inclusion criteria. The SENTINEL study excluded HLA-B27-negative patients with a single episode of AAU, while in our cohort, $11.1 \%$ of patients with newly diagnosed SpA met these exclusion criteria [9]. 
In accordance with the two above-mentioned studies, the prevalence of SpA was higher in our HLA-B27-positive patients than in those HLA-B27-negative (50\% vs. $15 \%, p<0.0001)$.

Moreover, the age at diagnosis of uveitis in HLA-B27positive patients was significantly lower than in patients with negative HLA-B27, in accordance with the SENTINEL study.

The multivariate logistic regression analysis for $\mathrm{SpA}$ diagnosis underlined as significant predictive factors age at diagnosis and HLA-B27 positivity.

Similarly to the SENTINEL study, we did not detect any important differences in the ophthalmologic features between subgroups, contrary to the study by Power et al. [9, 19]. According to Zaidi et al., patients with both a spondyloarthropathy and HLA-B27 positivity tend to have a higher risk of hypopyon than either factor alone [20]. In our study, both patients with hypopyon were HLA-B27 positive and classified as having axial SpA.

Since there are no commonly accepted clinical practice guidelines for rheumatology referral, HLA-B27 positivity in patients with anterior uveitis often represents an indication to recommend a rheumatological evaluation [21, 22]. Haroon et al. proposed the DUET algorithm for ophthalmologists evaluating patients with AAU as a tool for rheumatology referral (DUET algorithm, sensitivity 95\%, and specificity $98 \%$ [10]). According to this algorithm, the criteria suggesting rheumatologist referral are back pain lasting more than 3 months and onset at 45 years of age or older, or joint pain requiring a general practitioner's evaluation together with HLA-B27 positivity or coexisting psoriasis [10]. As this algorithm does not require any imaging evaluation such as sacroiliac X-rays or MRI and/or ultrasound of entheses and peripheral joints, ophthalmologists can easily use it in their daily clinical practice. In our cohort, 6 patients (17\%) with newly diagnosed SpA had a history of IBP or joint stiffness and pain but were negative for HLA-B27 and psoriasis. By applying the DUET algorithm, these patients would not have been evaluated for SpA. Therefore, SpA must be taken into consideration in HLA-B27-negative patients with anterior uveitis as well.

This was further confirmed that, regardless of HLA status, associated undiagnosed SpA must be suspected in the presence of IBP and/or signs and symptoms of peripheral arthritis in patients with NGAU.

According to Olivieri et al., the screening of patients presenting with NGAU for rheumatology referral plays a key role in the diagnosis and management of SpA [11], and red flags for referral have been outlined. Patients suffering from acute anterior nongranulomatous noninfectious uveitis should be evaluated by a rheumatologist when chronic low back pain has lasted more than 3 months or when there is a family/personal history of psoriasis involving the skin and/or nails and/or of SpA and/or IBD and/or Behçet's disease and/or oral and/or genital aphthae or erythema nodosum [11].

Furthermore, Sykes et al., using MRI to search for the presence of axial SpA in unselected patients presenting with $\mathrm{AAU}$, found a high prevalence of undiagnosed axial SpA in these patients, nearly half of whom were HLA-B27 negative.
These authors concluded that there does not appear to be a simple mechanism for screening these patients, and given the significant burden of 'hidden' axial SpA, recommend that ophthalmologists refer all patients with AAU with CBP onset at age $\leq 45$ years to rheumatology for further evaluation regardless of HLA-B27 status, sex, or number of episodes of AAU [23].

Our results confirm the high prevalence of undiagnosed SpA in patients with NGAU, suggesting that close collaboration between ophthalmologists and rheumatologists could improve the management of these patients.

In conclusion, regardless of HLA-B27 status, in the presence of IBP, as defined by ASAS experts and/or because of signs and symptoms of peripheral arthritis, patients with NGAU must be referred to the rheumatologist to allow earlier diagnosis. The Reggio Emilia Uveitis Spondyloarthritis Interdisciplinary Approach (REUSIA) algorithm, proposed in this study and under validation, may represent a new tool to guide the selection of appropriate candidates for referral to rheumatology and to allow earlier diagnosis.

Based on our experience, we recommend that the ophthalmologist, after a correct diagnosis of NGAU, refer all patients with HLA-B27 positivity and/or IPB and/or joint stiffness and pain and/or enthesitis (such as Achilles tendonitis or plantar fasciitis) and/or a history of psoriasis and/or IBD to rheumatology (REUSIA algorithm, Figure 1).

The study was limited by the small number of patients and the predominantly female sex of the patients. Prospective investigations to evaluate and validate this referral algorithm are needed.

\section{Data Availability}

Data are available on request.

\section{Conflicts of Interest}

All authors certify that they have no affiliations or involvement in any organization or entity with any financial interest (such as honoraria; educational grants; participation in speakers' bureaus; membership, employment, consultancies, stock ownership, or other equity interest; and expert testimony or patent-licensing arrangements) or nonfinancial interest (such as personal or professional relationships, affiliations, knowledge, or beliefs) in the subject matter or materials discussed in this manuscript.

\section{Authors' Contributions}

Pierluigi Macchioni and Giorgia Citriniti contributed equally to this work.

\section{References}

[1] J. H.-M. Chang and D. Wakefield, "Clinical report uveitis: a global perspective," Ocular Immunology and Inflammation, vol. 10, pp. 263-279, 2003.

[2] P. Pivetti-Pezzi, M. Accorinti, M. la Cava, R. A. M. Colabelli Gisoldi, and M. A. Abdulaziz, "Endogenous uveitis: an analysis 
of 1, 417 cases," Ophthalmologica, vol. 210, no. 4, pp. 234-238, 1996.

[3] A. Mercanti, B. Parolini, A. Bonora, Q. Lequaglie, and L. Tomazzoli, "Epidemiology of endogenous uveitis in North-Eastern Italy. Analysis of 655 new cases," Acta Ophthalmologica Scandinavica, vol. 79, no. 1, pp. 64-68, 2001.

[4] C. Luca, A. Raffaella, M. Sylvia et al., "Changes in patterns of uveitis at a tertiary referral center in northern Italy: analysis of 990 consecutive cases," International Ophthalmology, vol. 38, pp. 133-142, 2018.

[5] J. H. Chang, P. J. McCluskey, and D. Wakefield, “Acute anterior uveitis and HLA-B27," Survey of Ophthalmology, vol. 50, no. 4, pp. 364-388, 2005.

[6] C. P. Herbort, "Appraisal, work-up and diagnosis of anterior uveitis: a practical approach," Middle East African Journal of Ophthalmology, vol. 16, pp. 159-167, 2009.

[7] J. Rademacher, D. Poddubnyy, and U. Pleyer, "Uveitis in spondyloarthritis," Therapeutic Advances in Musculoskeletal Disease, vol. 12, 2020.

[8] R. Sen, A. Goyal, P. Bansal, and J. A. Hurley, Seronegtative Spondyloarthropathy, NCBI Bookshelf, 2020.

[9] X. Juanola, E. Loza Santamaría, and M. Cordero-Coma, "Description and prevalence of spondyloarthritis in patients with anterior uveitis: the SENTINEL interdisciplinary collaborative project," Ophthalmology, vol. 123, no. 8, pp. 1632-1636, 2016.

[10] M. Haroon, M. O'Rourke, P. Ramasamy, C. C. Murphy, and O. FitzGerald, "A novel evidence-based detection of undiagnosed spondyloarthritis in patients presenting with acute anterior uveitis: the DUET (Dublin Uveitis Evaluation Tool)," Annals of the Rheumatic Diseases, vol. 74, no. 11, pp. 19901995, 2015.

[11] On behalf of the CORE Study Group, I. Olivieri, M. Accorinti et al., "Standardization of red flags for referral to rheumatologists and ophthalmologists in patients with rheumatic diseases and ocular involvement: a consensus statement," Rheumatology International, vol. 38, no. 9, pp. 1727-1734, 2018.

[12] D. A. Jabs, R. B. Nussenblatt, J. T. Rosenbaum, and Standardization of Uveitis Nomenclature (SUN) Working Group, "Standardization of uveitis nomenclature for reporting clinical data. Results of the first international workshop," American Journal of Ophthalmology, vol. 140, pp. 509-516, 2005.

[13] M. Rudwaleit, R. Landewe, D. van der Heijde et al., “The development of assessment of spondyloarthritis international society classification criteria for axial spondyloarthritis (part I): classification of paper patients by expert opinion including uncertainty appraisal," Annals of the Rheumatic Diseases, vol. 68, no. 6, pp. 770-776, 2009.

[14] M. Rudwaleit, D. van der Heijde, R. Landewe et al., "The development of assessment of spondyloarthritis international society classification criteria for axial spondyloarthritis (part II): validation and final selection," Annals of the Rheumatic Diseases, vol. 68, no. 6, pp. 777-783, 2009.

[15] V. Masson Behar, M. Dougados, A. Etcheto et al., "Diagnostic delay in axial spondyloarthritis: a cross-sectional study of 432 patients," Joint Bone Spine, vol. 84, no. 4, pp. 467-471, 2017.

[16] S. S. Zhao, B. Pittam, N. L. Harrison, A. E. Ahmed, N. J. Goodson, and D. M. Hughes, "Diagnostic delay in axial spondyloarthritis: a systematic review and meta-analysis," Rheumatology, vol. 60, no. 4, pp. 1620-1628, 2021.
[17] M. R. Seo, H. L. Baek, H. H. Yoon et al., "Delayed diagnosis is linked to worse outcomes and unfavourable treatment responses in patients with axial spondyloarthritis," Clinical Rheumatology, vol. 34, no. 8, pp. 1397-1405, 2015.

[18] R. Aggarwal and A. N. Malaviya, "Diagnosis delay in patients with ankylosing spondylitis: factors and outcomes - an Indian perspective," Clinical Rheumatology, vol. 28, no. 3, pp. 327331, 2009.

[19] W. J. Power, A. Rodriguez, M. Pedroza-Seres, and C. S. Foster, "Outcomes in anterior uveitis associated with the HLA-B27 haplotype," Ophthalmology, vol. 105, no. 9, pp. 1646-1651, 1998.

[20] A. A. Zaidi, G. S. Ying, E. Daniel et al., "Hypopyon in patients with uveitis," Ophthalmology, vol. 117, no. 2, pp. 366-372, 2010.

[21] A. Calin, J. F. Fries, D. Schurman, and R. Payne, "The close correlation between symptoms and disease expression in HLA B27 positive individuals," The Journal of Rheumatology, vol. 4, 1977.

[22] A. B. Beckingsale, J. Davies, J. M. Gibson, and A. R. Rosenthal, "Acute anterior uveitis, ankylosing spondylitis, back pain, and HLA-B27," The British Journal of Ophthalmology, vol. 68, no. 10, pp. 741-745, 1984.

[23] M. P. Sykes, L. Hamilton, C. Jones, and K. Gaffney, "Prevalence of axial spondyloarthritis in patients with acute anterior uveitis: a cross-sectional study utilising MRI," RMD Open, vol. 4, no. 1, pp. 1-7, 2018. 